\title{
Use of Liposome Entrapped Triethylenetetramine (TETA) in the Treatment of Mice Loaded with Nickel Chloride
}

\author{
Key words: Nickel intoxication - Chelation - Liposomal - Triethylenetetramine \\ (TETA)-Mice
}

Interest in nickel metabolism mainly stems from its toxicity and undetermined role as an essential trace element in animals. ${ }^{11}$ Nickel induced respiratory disorders and its carcinogenic potential have been reviewed in detail. ${ }^{2-5)}$ Several chelating agents have been examined for their therapeutic potential in the treatment against nickel intoxication and diethyldithiocarbamic acid (DDC) has been reported to be the most effective antidote against nickel carbonyl poisoning. ${ }^{6}$ ) This is due to increased permeability of DDC through cell membrane providing access to intracellular nickel compared to chelating agents of the polyaminocarboxylic acid series. ${ }^{7)}$ An evaluation of the ability of the chelating agents to prevent death in rats after single parenteral injection of nickel chloride has shown that penicillamine and triethylenetetramine (TETA) possess similar efficacy and were superior to other chelators including DDC. ${ }^{8)}$ The efficacy of TETA against intoxication with nickel salts has been appreciated in other studies also. ${ }^{9)}$ Since polyaminocarboxylic acids are mostly distributed extracellularly and their rate of excretion is much faster than the liposome entrapped material, ${ }^{10}$ it was considered worthwhile to make use of liposomes for longer retention of the chelator in body to ensure consistent and safe removal of the accumulated metal by presenting the kidneys with a lower concentration of the metal chelator complex for clearance into the urine.

Egg phosphatidyl-choline (PC), cholesterol, triethylenetetramine and nickel chloride were obtained from sigma. Radiolabelled ${ }^{63} \mathrm{NiCl}_{2}$ and $\mathrm{NCS}$ tissue solubilizer were obtained from Amersham International (U.K.). Male mice (22$25 \mathrm{~g}, 10$ weeks old) were given two intraperitoneal injections of nickel chloride $\left(17 \mu\right.$ mole $\mathrm{Ni} / \mathrm{kg}$ as $\mathrm{NiCl}_{2} \cdot 6 \mathrm{H}_{2} \mathrm{O}$ with $486 \mu \mathrm{Ci}{ }^{63} \mathrm{NiCl}_{2}$, Sp. Act. $11.28 \mathrm{mCi} / \mathrm{mg}$ ) at an interval of 24 hours. They were divided into three groups and administered i.v. either physiological saline, TETA $(0.272 \mathrm{mmole} / \mathrm{kg})$ or TETA via liposomes $(0.272$ mmole TETA with $64.8 \mu$ mole lipid $/ \mathrm{kg}) 24$ hours following the last injection of nickel chloride. Five animals from each group were sacrificed at 24, 72 and 144 hours following the treatment. The liver, kidneys and spleen were taken out and homogenised in distilled water. One $\mathrm{ml}$ aliquots of the tissue homogenate were transferred in duplicate to the scintillation vials and mixed with $2.5 \mathrm{ml}$ of NCS tissue solubilizer. The samples were allowed to digest over-night at room temperature followed by addition of $17 \mathrm{ml}$ scintillant. They were mixed and dark adapted for 24 hours before counting of ${ }^{63} \mathrm{Ni}$ radioactivity 
on LKB scintillation spectrometer. Liposomal TETA was administered through dehydration-rehydration vesicles prepared in the following manner. ${ }^{11)}$ Small unilamellar vesicles (16.2 $\mu$ mole lipids) derived from equimolar egg phosphatidylcholine and cholesterol together with 0.068 mmole TETA (pH adjusted to 7.0 with $1 \mathrm{~m} \mathrm{HCl}$ ) were freeze dried and subjected to controlled rehydration. The resulting suspension so obtained was raised to $1 \mathrm{ml}$ volume with phosphate buffered saline and $0.1 \mathrm{ml}$ was injected to $25 \mathrm{~g}$ mouse.

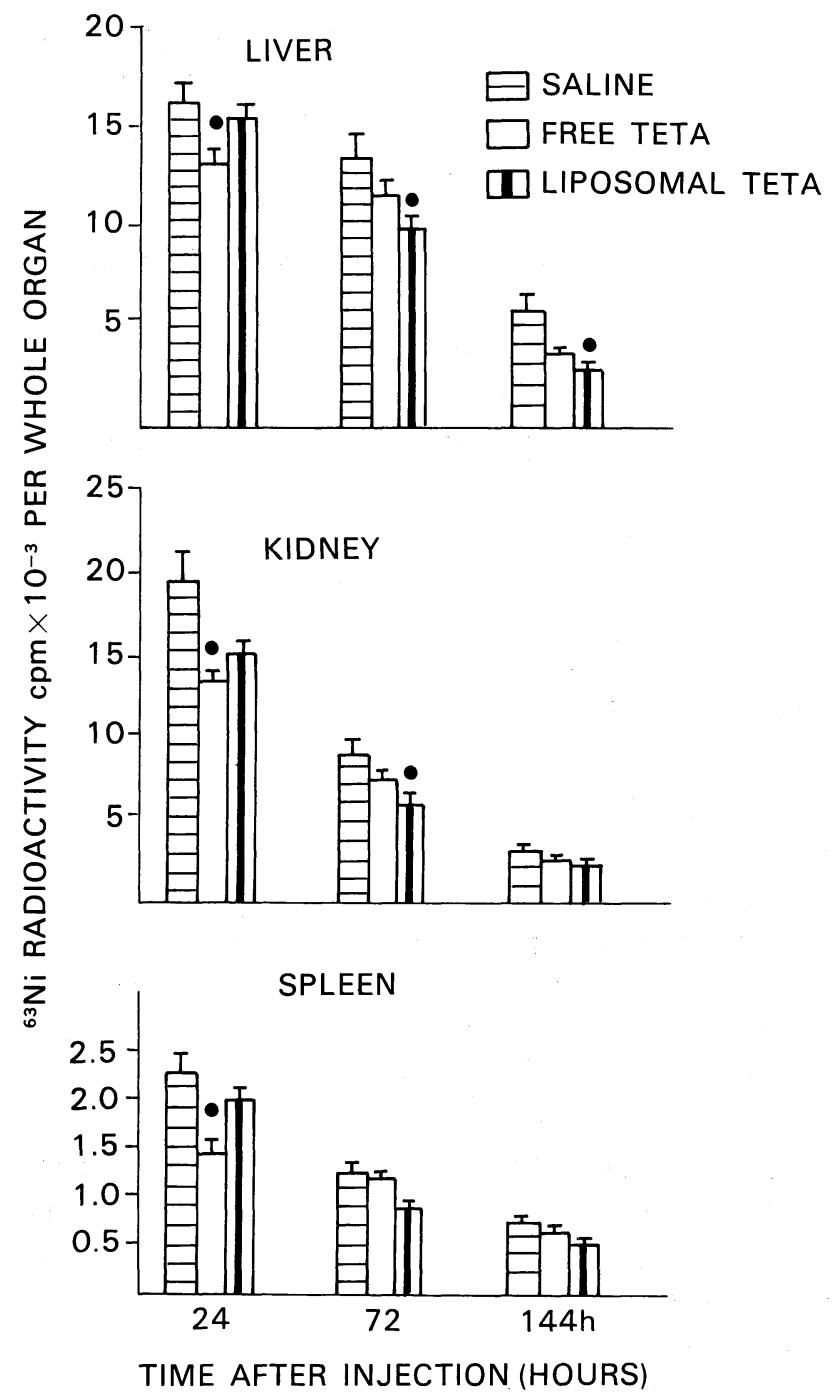

Fig. 1. Effect of triethylene tetramine (TETA) administration (free or via liposomes) on tissue levels of ${ }^{63} \mathrm{Ni}$ among nickel chloride loaded mice. Each value is a mean $\pm S E$ of five mice $p<0.05$ when compared to saline control. 
The pattern of ${ }^{63} \mathrm{Ni}$ radioactivity in tissues of the nickel treated mice at different time intervals after treatment with TETA is shown in the Fig. 1. The levels of ${ }^{63} \mathrm{Ni}$ in liver kidneys and spleen were significantly lowered 24 hours after the treatment with free TETA compared to those obtained after the treatment with saline while no appreciable change was observed with liposomal TETA. However 72 hours post treatment liposomal TETA was effective in reducing significantly the level of ${ }^{63} \mathrm{Ni}$ in the liver and kidneys compared to physiological saline treatment, which was not the case in animals treated with the free material. Although free TETA resulted in the lowering of ${ }^{63} \mathrm{Ni}$ in spleen at 24 hours after treatment, there seems to be no effect of either free or liposomal TETA in spleen beyond $24 \mathrm{hrs}$. It was shown that TETA administered via liposomes was effective over a longer duration compared to the free material in so far as removal of nickel from liver and kidney was concerned. Free TETA seemed to be relatively more effective within first 24 hours which might be due to its faster distribution and excretion compared to liposomal TETA. It could thus be expected that liposomal entrapment of chelating agents of polyaminocarboxylic acid series including TETA might be helpful in altering the course of metal removal rendering chelation therapy more effective and safe compared to the use of free drug.

\section{AcKNowledgment}

The author is grateful to the Wellcome Trust London for financial support to work at the MRC group, Academic Department of Medicine, Royal Free Hospital School of Medicine, London where the work was carried out.

\section{RefERENCES}

1) Schnegg A, Kirchgessner M. Changes in the hemoglobin content, erythrocyte count and hematocrit in nickel deficiency. Nutr Metab 1975; 19: 268-78.

2) Tatarskaya AA. Occupational diseases of upper respiratory tract in persons employed in nickel refining departments. Gig Tr Prof Zabol 1960; 6: 35-8.

3) Furst A, Radding SB. An update on nickel carcinogenesis. In: Nriagu J.O., ed. Nickel in the Environment. New York, John Wiley and Sons, 1980; 585-600.

4) Sunderman FW Jr. Recent research on nickel carcinogenesis. Environ Health Perspectives 1981; 40: 131-42.

5) Doll R, Morgan LG, Speizer FE. Cancers of the lung and vasal sinuses in nickel workers. Brit J Cancer 1970; 24: 623-32.

6) Sunderman FW Jr. Chelation therapy in nickel poisoning. Ann Clin Lab Sci 1981; 11: $1-8$.

7) May PM, Bulman RA. The present status of chelating agents in medicine. In: Ellis GP, West GB, eds. Progress in Medicinal Chemistry. Amsterdam: Elsevier Science Publishers, 1983; 20: 225-336.

8) Horak E, Sunderman FW Jr, Sarkar B. Comparison of antidotal efficacy of chelating drugs upon acute toxicity of $\mathrm{Ni}$ (ii) in rats. Res Comm Chem Pathol Pharmacol 1976; 
14: $153-65$.

9) Basinger MA, Jones MM, Takka MP. Relative efficacy of chelating agenst as antidotes for acute Ni (ii) acetate intoxication. Res Comm Chem Pathol Pharmacol 1980; 30: $133-41$.

10) Jonah MM, Cerny EA, Rahman YE. Tissue distribution of EDTA encapsulated within liposomes of varying surface properties. Biochim Biophys Acta 1975; 401: 336-48.

11) Kirby C, Gregoriadis G. Dehydration-rehydration vericles: A simple method for high yield drug entrapment in liposomes. 1984; 2 : 979-84.

Industrial Toxicology Research Centre,

Jai Raj BEHARI

Post Box 80, Mahatma Gandhi Marg,

Lucknow-226 001, India

(Received May 6, 1987 and in revised form July 20, 1987) 